IZA DP No. 1981

Screening Disability Insurance Applications

Philip de J ong

Maarten Lindeboom

Bas van der Klaauw

February 2006 


\title{
Screening Disability Insurance Applications
}

\author{
Philip de Jong \\ Aarts, De Jong, Wilms \& Goudriaan Public Economics B.V. \\ and University of Amsterdam \\ Maarten Lindeboom \\ Free University Amsterdam, Tinbergen Institute, \\ HEB, Netspar and IZA Bonn \\ Bas van der Klaauw \\ Free University Amsterdam, Tinbergen Institute, \\ Scholar, IFAU, CEPR and IZA Bonn
}

Discussion Paper No. 1981
February 2006

IZA

P.O. Box 7240

53072 Bonn

Germany

Phone: +49-228-3894-0

Fax: +49-228-3894-180

Email: iza@iza.org

\begin{abstract}
Any opinions expressed here are those of the author(s) and not those of the institute. Research disseminated by IZA may include views on policy, but the institute itself takes no institutional policy positions.

The Institute for the Study of Labor (IZA) in Bonn is a local and virtual international research center and a place of communication between science, politics and business. IZA is an independent nonprofit company supported by Deutsche Post World Net. The center is associated with the University of Bonn and offers a stimulating research environment through its research networks, research support, and visitors and doctoral programs. IZA engages in (i) original and internationally competitive research in all fields of labor economics, (ii) development of policy concepts, and (iii) dissemination of research results and concepts to the interested public.
\end{abstract}

IZA Discussion Papers often represent preliminary work and are circulated to encourage discussion. Citation of such a paper should account for its provisional character. A revised version may be available directly from the author. 
IZA Discussion Paper No. 1981

February 2006

\section{ABSTRACT}

\section{Screening Disability Insurance Applications}

This paper investigates the effects of intensified screening of disability insurance benefit applications. A large-scale experiment was setup where in 2 of the 26 Dutch regions case workers of the disability insurance administration were instructed to screen applications more intense. The empirical results show that intense screening reduces long-term sickness absenteeism and disability insurance applications. This provides evidence both for direct effects of the more intensive screening on work resumption during sickness absenteeism and for self-screening by potential disability insurance applicants. We do not find any spillover effects to the inflow into unemployment insurance. A cost-benefit analysis shows that the costs of the intensified screening are only a small fraction of its benefits.

JEL Classification: J28, J65

Keywords: disability insurance, experiment, policy evaluation, sickness absenteeism, self-screening

Corresponding author:

Bas van der Klaauw

Department of Economics

Free University Amsterdam

De Boelelaan 1105

NL-1081 HV Amsterdam

The Netherlands

Email: klaauw@tinbergen.nl

\footnotetext{
* The authors thank Jonneke Bolhaar for excellent research assistance. We furthermore would like to thank John Bound, Norma Coe and participants at seminars at Uppsala University and Utrecht University for useful comments and suggestions.
} 


\section{Introduction}

In most OECD countries disability insurance (DI) programs are substantial in size and have experienced strong growths in the recent decades (OECD, 2003). The Dutch DI program used to be an extreme example of uncontrolled growth. In the early seventies, less than $4 \%$ of the working age population was collecting DI benefits. This number increased to about $10 \%$ in the beginning of the nineties and since then, despite a series of policy measures, remained around the same level. ${ }^{1}$ This makes it the largest and most expensive social insurance program in the Netherlands and a recurrent topic of in political debate.

Over the time period we consider, sick employees had a one year waiting period before entering the DI Scheme. During this period employers are responsible for financing sick pay. ${ }^{2}$ After 13 weeks of sickness absence the employer reports the sick employee to the National Social Insurance Institute (NSII), the public administrator of the unemployment insurance (UI) and DI schemes. If the worker has not fully returned to work before 39 weeks, the worker and employee file a DI benefit claim. Recently the role of the NSII changed. Until April 2002 the NSII had during the waiting period of sickness absenteeism a joint responsibility with the sick worker and the employer to get the sick worker back to work. Since April 2002, the NSII is no longer involved during the waiting period. DI benefit applications should be accompanied by a reintegration report, containing the reintegration plan as drafted after 8 weeks of sickness absenteeism, and an assessment on why it has not (yet) resulted in work resumption. The case worker of the NSII checks this reintegration report. If the report is delayed, incomplete, or proves that the reintegration efforts by the sick worker and employer have been insufficient the DI benefit application is not processed and the case worker of the NSII can decide to start a sanction procedure. In almost all cases of noncompliance the employer is hold responsible, which means that almost all sanctions are imposed on employers. A sanction to the employer implies that the employer is obliged to continue sick pay for some additional months after the regular waiting period elapsed. Sanctions to the worker are rare, but these imply that the worker receives a reduced benefit level during the first few months of collecting DI benefits.

DI programs are often subject to moral hazard (e.g. Bound and Burkhauser, 1999). When the costs of applying for DI benefits are relatively low, a generous DI program may cause workers to use DI as a channel to leave the labor force and employers to use DI to lay off redundant workers. Furthermore, when there is no or little screening of DI applications, employers may decide to devote none or only a minimal effort in trying to get sick employees back to work. Intensive screening of the reintegration reports accompanying the DI application procedure can overcome both moral hazard problems. First, it forces employers to devote serious

1 For the population aged 55 years and older DI rates were as high as $22 \%$ in the mid 1990s.

2 Collective bargaining agreements ensure that sick workers receive 90 to $100 \%$ of their net salary. Most employers have insured themselves against financing sick pay. Employers are obliged to contract an occupational health agency for managing sickness absenteeism and the doctors of these agencies check the legitimacy of sickness absenteeism. 
effort to getting sick workers back to work before they enter the DI program. If reintegration activities are effective, then the increased effort positively affects work resumption during sickness absenteeism. Second the intensified screening of the reintegration reports reduces the attractiveness of the DI program to potential applicants (and to their employers). This reduced attractiveness of DI may trigger a mechanism of self-selection or self-screening among potential applicants. Halpern and Hausman (1986) and Parsons (1991) point towards the effect of lower acceptance rates on self-screening. Johansson and Palme (2002) show for Sweden that reducing sick pay decreases the inflow into sick-pay schemes.

In this paper we investigate the effects of intensified screening of the reintegration reports on long-term sickness absence (measured by the number of workers who have been sick for 13 consecutive weeks) and on DI benefit applications. For this we have set up an experiment, where we instructed the case workers at the local offices of the NSII in two out of 26 regions in the Netherlands to implement a more intensive screening policy of the reintegration reports. The standard (national) procedure was to screen the reintegration reports "on paper" and to only contact the employer and/or sick worker directly if there were clear signals of negligence. In the two treatment regions the case workers always had to contact or visit the employer and/or the sick employee. We monitored the behavior of the case workers to check that screening in the treatment regions was indeed more intensive than in the rest of the Netherlands. In the treatment regions the time spent on screening reintegration reports by the case workers was $40 \%$ higher than in the control regions. Previous research in this area mostly relies on regional variation in (the implementation of) DI rules (e.g. Autor and Duggan, 2003; Gruber, 2000; and Parsons, 1991). ${ }^{3}$ As far as we know this is the first controlled experiment in which regional variation is determined truly exogenously.

Our data are from the administrative records of the NSII and cover the period from 2001 until 2003. The more intensive screening of reintegration reports became effective in January 2003 and was not announced beforehand. In the empirical analyses we use both difference-indifference analyses at the level of the regions and estimate more parameterized Logit models at the individual level. We find that the intensified screening decreases long-term sickness absenteeism and DI applications equally. We argue that the reduction in long-term sickness absenteeism is due to self-screening by potential DI applicants and that for DI applications the decline is due to a direct effect on work resumption during sickness absence. There may be negative spillover effects between DI and UI inflow, for example Autor and Duggan (2003) find that DI inflow is negatively related to UI inflow. We do not find that intensified screening induces a larger inflow into UI. A cost-benefit analysis shows that the costs of the intensified screening are only a small fraction of its benefits measured as the averted DI benefits payments.

The outline of this paper is as follows. In Section 2 we provide some institutional background concerning the Dutch DI system. Section 3 discusses the setup of the experiment.

3 A possible drawback of relying on this kind of identification is that the changes in the state specific DI rules may depend on previous DI outcomes and that therefore the variation in the rules is not entirely exogenous. 
Section 4 gives some theory. In Section 5 we discuss the administrative database that will be used in the empirical analyses. In Section 6 we present our estimation results. Section 7 concludes.

\section{Institutional background}

In this section we describe the Dutch DI system as it was in 2003, the year of our experiment. Furthermore, we discuss the reintegration activities to which sick workers and their employers have to comply. We only discuss aspects that are relevant for this study.

\section{$2.1 \quad$ DI benefits}

The Dutch DI program covers all employees. Any illness or injury entitles to entering DI after a mandatory waiting period of one year. While other OECD countries make a distinction by whether the impairment occurred on the job or elsewhere, only the consequence of impairment is relevant for the Dutch disability insurance program. The degree of disablement does not depend on the injury or illness, but is assessed by considering the worker's residual earning capacity. This residual earnings capacity is defined by the potential earnings with the injury or illness as fraction of the pre-sickness earnings, thus irrespective of one's work history. The degree of disablement is the complement of the residual earning capacity. Entitlement to DI benefits requires a minimum rate of disablement of $15 \%$. The DI program distinguishes seven classes of benefits levels. Wage replacement rates range from $14 \%$ for a degree of disablement between 15 and $25 \%$ to $70 \%$ for a degree of disablement between 80 and $100 \%$. The entitlement period of these benefits depend on the worker's age at onset of disability. This entitlement period varies from 0 years for those under age 33 to 6 years for individuals over age 58 .

After expiration of these initial benefits, the disabled worker receives lower follow-up benefits. These follow-up benefits have an unlimited entitlement period and the level is determined by the earlier wage replacement rate $*$ (minimum wage + supplement). The supplement is given by the formula: $0.02 *$ (age of disability onset -15$) *$ (wage - minimum wage), where wage is the worker's pre-sickness wage. However, most collective bargaining agreements cover the gap between these lower benefits and the initial benefits. The collective bargaining agreements force employers to insure their workers for this gap. All DI benefits have a maximum of 43,770 euro per year (for a degree of disablement above $80 \%$ ). Individuals collecting DI benefits are not obliged to search for work. This and the unlimited entitlement to DI benefits make DI more attractive to individuals than UI. UI benefits have a limited entitlement period, after which the individual should apply for means-tested welfare benefits.

Figure 1 shows the number of individuals collecting DI benefits as a percentage of the working age population and the inflow rate into DI. The figure shows a sharp increase in the percentage of individuals collecting DI benefits in the Seventies and Eighties. The number of beneficiaries increased from 475,000 in 1976 to 921,000 in 1993. During the Nineties, there have 
been some changes in the disability definition and the calculations of benefits. This reduced the inflow into DI. Furthermore, part of the stock of beneficiaries was reexamined using the new more stringent disability definitions. This increased the number of benefit terminations and, on balance, led to a 7\% drop in the number of beneficiaries to 855,000 in 1996. From then on the numbers started growing again and reached 979,000 in November 2002, coming close to the politically contentious level of one million disabled.

\subsection{Reintegration reports}

As of April 2002, the role of the NSII has changed. The new protocol specifies the responsibilities of the sick employee and his/her employer towards early interventions after reporting ill. After a maximum of six weeks of absence a doctor employed by an occupational health agency has to make a first assessment of medical cause, functional limitations and give a prognosis regarding work resumption. The sick worker and employer use the doctor's assessment to draft a reintegration plan, which specifies an aim (resumption of current/other job under current/accommodated conditions) and the steps towards this aim. They appoint a case-manager (often from the occupational health agency), and fix dates at which the plan should be evaluated, and modified if necessary. The reintegration plan is binding for both the employer and worker and should be ready in the eighth week of sickness absenteeism. After 13 weeks of absence the employer should report the sick employee to the NSII, which is only a paper obligation.

If the employer did not report work resumption before 35 weeks of sickness absenteeism the NSII sends a DI application form to the sick worker. DI claims have to be delivered no later than the $39^{\text {th }}$ week of sickness. Claims are only considered admissible if accompanied by a reintegration report, containing the original reintegration plan and an assessment why it has not (yet) resulted in work resumption. If the report is delayed, incomplete, or proves that the reintegration efforts are insufficient the claim is not processed. Depending on the seriousness of the negligence the case worker can give the possibility to complete the reintegration report or to start a sanction procedure.

Officially the employer and the sick employee are jointly responsible for reintegrating the sick worker. However, in most cases the NSII will hold the employer responsible in case of negligence. An employer has the right to fire a employee who refuses to collaborate to execute the reintegration plan, and the case worker will ask the employee why this has not happened if it is clear that the employee did not comply. In practice this implies that almost all sanctions are imposed on employers. Employer's sanctions mean an extension of the period during which the employer pays sickness benefits by three to twelve months.

\section{Experiment}

Our experiment period started January 1, 2003. At this date the first DI applications under the 
April 2002 reform arrived at the regional offices of the NSII. These were the first DI applications that were accompanied by reintegration reports. In 2 out of the 26 regions we instructed the case workers to implement a more intensive screening policy of reintegration reports than in the rest of the Netherlands. The standard (national) procedure is to screen the reintegration reports "on paper" and to only contact the employer and/or sick worker directly if there are clear signals of negligence. In the two treatment regions we instructed the case workers to always contact or visit the employer and/or the sick employee, unless it was absolutely clear that, given the medical condition, sufficient efforts were undertaken. ${ }^{4}$ The intensified screening was only applied to individuals who had not resumed work for more than $50 \%$ of their contractual working hours and were not severely and permanently disabled (according to the doctor of the occupational health agency). The experiment period finished at the end of October 2003. We have set up the experiment together with the NSII. The experiment was never reported to the employers, worker, the occupational health agencies or in the press. We designed the experiment, but the treatment regions were assigned to us by the NSII. The treatment regions were not selected randomly, but instead the NSII chose two regions that are supposed to be representative for the Netherlands. In Section 5, we use pre-experiment outcomes of sickness absenteeism, DI application and UI inflow to investigate if treatment assignment was actually independent of these outcomes.

The start of the experiment coincided with the introduction of the new DI act. Before this new act, case workers of the NSII were actually involved in the reintegration activities during the period of sickness. Therefore, instead of checking reintegration effort afterwards, the NSII had a jointly responsibility with the employer and sick worker for the reintegration efforts during sickness absence. This implies that at the start of our experiment case workers did not have any experience in screening reintegration reports. For the success of the experiment it is crucial that in the treatment regions the screening regime is implemented more intense than in the rest of the Netherlands. To monitor the screening regimes in all regions we sent out questionnaires to both the treatment and the control regions. In the treatment regions we required case worker to fill out a questionnaire for each DI application. This was done not only to monitor their behavior but also to keep their attention to the intense screening. In the control regions we asked the local managers to regularly report summaries of the screening regime. Table 1 summarizes the difference in screening intensity in the treatment and the control regions. The table shows that in the treatment regions case workers visited sick workers (Apeldoorn region) or their employers (Hengelo region) more often than elsewhere. ${ }^{5}$ In the control regions reintegration reports are checked more often only on paper or by phone. Since visits are considered to be the most intensive screening, this confirms that screening was indeed more intensive in the treatment regions.

4 The main reason to screen a reintegration report only "on paper" in the treatment regions is that the case worker already handled multiple applicants from an employer and that therefore the case worker is familiar with the reintegration protocol of this employer.

$5 \mathrm{We}$ return to the difference in screening methods between the two experiment regions in Subsection 6.4. 


\section{Theoretical background}

Employers are financially responsible for sick pay during the first 12 months of absence. The employer drafts together with the sick worker a reintegration plan, but usually it is the employer who decides on reintegration activities and workplace accommodations needed to stimulate work resumption. We therefore take the employer as the relevant decision making agent and hence assume that workers comply with the measures provided by the employer.

The change in legislation in April 2002 imposes minimum requirements on reintegration efforts that the employer should offer and the employer is at risk of getting a sanction if the actual reintegration efforts do not meet these minimum requirements. The probability of getting a sanction and the size of the sanction increase with the extent of noncompliance.

Reintegration efforts are costly to employers, as they are mandated to contract a private provider of occupational health agencies to manage absenteeism. Physicians employed by occupational health agencies check whether the absence from work is legitimate and give a prognosis concerning work resumption. The case managers of the reintegration process during sickness absence are often employees from the occupational health agencies. The occupational health agencies usually work for many different employers and thus collect and transmit information about the policy of the local offices of NSII between employers. We return to this issue below.

Employers choose their reintegration activities such that the marginal costs equal marginal returns. The returns to reintegration activities are not only reduced threats of getting a sanction, but if reintegration activities are effective, also the probability of work resumption increases and sick pay will be lower. Of course, introducing intensive screening and sanctions does not change the employer's behavior if the optimal reintegration activities already exceed the minimum requirements imposed by the NSII. However, if these optimal reintegration activities are below the minimum requirements, more intensive screening and a stricter sanction regime induce employers to increase reintegration effort. After all, both the probability of getting a sanction and the size of a sanction increase with the degree of noncompliance. If intensified screening leads to increased reintegration activities and if these activities are effective, work resumption rates increase and DI application rates decrease. This is a direct effect of intensified screening.

More intensive screening also reduces the attractiveness of the DI program to all potential applicants and may trigger a mechanism of self-selection or self-screening (Parsons, 1991). The decision to start a DI application process involves a comparison of expected utilities of alternatives, such as unemployment, early retirement or continuing work. Intensified screening increases the costs of applying for a DI benefits. Self-screening may induce potential applicants who think that their DI application might not meet the eligibility requirements not to apply for the program. Indeed, Parsons (1991) finds empirically that self-screening is important in explaining fluctuations in the inflow into DI in the US.

If self-screening is important, we should observe a decrease in reports after 13 weeks of sickness absenteeism due to the intensified screening. If direct effects of screening are important, 
then we should find that a substantial share of the people who report sick recover between week 13 and week 39 when applying for DI benefits. Recall that reintegration plans are drafted after 8 weeks of sickness absence. Therefore, the impact of the reintegration activities on work resumption will mainly be concentrated after 13 weeks. A possible consequence of self-screening is that workers who without intensified screening would have applied for the DI program will apply instead for other programs like UI. Autor and Duggan (2003) find substantial spillovers between DI and UI programs in the US. If this is also relevant here, we expect to find higher UI inflow rates in the treatment regions.

The effect of stricter screening on the sanction rate is ambiguous. In the treatment regions noncompliance with the minimum requirements is more likely to be detected. This implies more sanctions due to stricter screening. However, self-screening and increased reintegration activities due to the intensified screening are expected to reduce noncompliance in the treatment regions. It remains unclear which of these effects dominates.

The experiment started in January 2003, when the regime change for the NSII for handling DI applications became effective. Because of the regime change employers, workers and occupational health agencies in both the treatment and control regions did not have any experience with the minimum requirements and sanction risks at different levels of reintegration activities. Moreover, employers, employees and occupational health agencies were never informed about the experiment. Therefore, at the start of the experiment employers in the treatment and in the control regions are expected to display the same behavior. However, in the treatment regions sanction probabilities are higher and therefore employers are notified faster about noncompliance. Employers in the treatment regions should thus learn faster about the minimum reintegration activities requirements. The occupational health agencies serve many different employers and they collect and transmit information about changes in scrutiny at the regional offices of the NSII. Therefore, employers not only learn through their own experience, but also through information disseminated by the occupational health agencies.

The experiment is not continued after 2003 and we also do not have data later than 2003. As discussed in the next section we observed the year in which a worker applies for DI benefits, but not the exact date. This implies that many of the DI applications that are observed are from workers who first reported sick in 2002 or at the start of 2003 when employers and workers had not yet learned about the details of the screening policy. This implies that self-screening at the start of the DI application process (if present) is most likely not yet reflected in the DI application rates of 2003. The reductions in 2003 DI application rates due to intensified screening is therefore a measure for the effect of the increased reintegration activities on work resumption during sickness absenteeism. Thirteen week absence reports are much less affected by the direct effects of increased reintegration activities and therefore the effect of the stricter screening on these reports should be interpreted as the consequence of increased self-screening. However, also the 2003 reports on 13 weeks sickness absenteeism includes reports from workers who became sick at the end of 2002 or the very beginning of 2003 and therefore our estimated effects will most likely be underestimates for the long-run effect of intensified screening. 


\section{Data}

Our data are from the administrative records of the NSII and describe the period 2001-2003. For each year, the data contain all insured individuals in 45 sectors of industry, which covers around $50 \%$ of the Dutch working population. ${ }^{6}$ Not included are branches like construction, retail, and health care. Stratified by age, gender, sector of industry and region, we observe (1) the number of insured individuals on January 1 of each year, (2) the number of 13 weeks sickness reports during the year, (3) the number of DI applications during the year and (4) the number of individuals flowing into UI during the year. The setup of the data does not allow us to identify specific individuals and therefore we do not have a true panel data structure at the individual level.

Table 2 provides some descriptive statistics of the data. During our observation period GDP growth rates were low, which is reflected in the data. The insured population, 13 weeks sickness absence and the number of DI applications decreased, while the inflow into UI increased. The sanction rate is only observed in 2003, since sanctions were newly introduced when the new law became effective. The data on sanctions only describe the total number of sanctions given in each region. Therefore, we cannot link the sanctions to specific individuals. The sanction rate is the number of sanctions as a fraction of the number of DI applications. The fraction of females remained constant over time, but over the years the insured population aged. The latter can be the consequence of both reduced opportunities for early retirement (e.g. OECD, 2004) and less job opportunities for school leavers and young workers.

As mentioned in Section 3 the treatment regions were not randomly selected, but rather assigned by the NSII. It is important to check if the choice of the treatment regions is unrelated to relevant outcome measures. Recall that the intensified screening of reintegration reports started on January 2003. Therefore, we can use the pre-experiment years 2001 and 2002 to investigate random assignment. In Table 3 we show for 2002 the outcomes in the treatment and the control regions. The treatment regions do not differ substantially with respect to the outcome variables from the control regions, although sickness absenteeism is somewhat higher and UI inflow is slightly lower. The main goal of the intensified screening is to reduce the DI application rate. Since the table shows that DI application rates were virtually identical, we can conclude that the treatment regions were not selected on their DI application rates (or any other relevant outcome) in 2002.

Our data describe multiple years and therefore to estimate the effect of the intensified screening we only need random selection of the treatment regions conditional on regional fixed effects. A simple test for this conditional random assignment is to check if in the treatment regions the outcome variables changed differently between the pre-experiment years 2001 and

6 Traditionally, the NSII had different organizations for different sectors of industry. These organizations are officially integrated, but case workers are still connected to particular sectors of industry and the databases of the different organizations are not yet merged. In the experiment, we only instructed the case workers handling these 45 industries, 
2002 than in the control regions. More specifically, we take the panel data model at the level of the region for the years $t$ is 2001 and 2002:

$$
Y_{r, t}=\alpha+\beta \text { Year }+\gamma \text { Treatment }_{r, t}+\delta_{r}+\mathrm{u}_{\mathrm{r}, \mathrm{t}}
$$

where $\beta$ describes the nation wide time trend, Treatment $t_{r, t}$ is an indicator that only equals 1 in the treatment regions in the year 2002 and $\delta_{r}$ is the regional specific effect. We estimated this equation in first-differences:

$$
Y_{r, 2002^{-}} Y_{r, 2001}=\beta+\gamma \text { Treatment }_{r}+e_{r}
$$

The estimation results in Table 4 show that the outcomes in the treatment regions did not significantly change from those in the control regions. We therefore conclude that the selection of the treatment regions is exogenous with respect to pre-experiment outcomes.

\section{$6 \quad$ Results}

In this section we first discuss the effects of the intensified screening on 13 weeks sickness reports and DI applications. Next, we investigate how the sanction rate is affected by more intensive screening, whether there are spillovers towards UI inflow and we report on some additional analyses. We finally report on the results of a simple cost-benefit analysis.

\subsection{Effects on sickness absence and DI applications}

Our main parameters of interest are the effects of intensified screening on 13 weeks sickness absenteeism reports and DI applications. Recall from Section 4 that our data only allow us to measure this effect during the first year after the intensified screening was introduced. Therefore, we are likely to underestimate the long-run effects of the intensified screening.

In Table 5 we present the results from difference-in-difference analyses. For each region we use as outcomes the number of 13 weeks sickness absenteeism reports and the number of DI applications as fraction of the insured population in the pre-experiment year 2002 and the experiment year 2003. Effectively we estimate equation (2). The trend effects show that both the probability that a worker reports sick and the probability that a worker applies for a DI benefits decrease significantly between 2002 and 2003. This may be the result of the nationwide regime shift that occurred in April 2002 and became effective in January 2003. But it might as well be the result of as adverse macroeconomic conditions. Absence rates are found to be pro-cyclical (e.g. Johansson and Palme, 1996) and the Dutch economy was in a recession during our period of observation. From the table we see that the intensified screening causes a decrease in sickness absenteeism reports and in DI applications. However, only the effect on sickness absence is 
significant.

In the empirical analyses above we only used regional variation and we have not exploited the individual characteristics observed in the dataset. We have also estimated Logit models for the individual probability of 13 week sickness and the probability to apply for DIbenefits. Other than the indicator for intensified screening, we include as regressors a nationwide time trend, regional indicators, the gender of the individual interacted with age dummies, sector dummies and sector dummies interacted with time trends. The latter set of variables allow for different sectoral trends between 2002 and 2003. Table 6 shows the marginal effects from the estimated Logit models. We see little changes in the effect of more intensive screening when we compare the difference-in-difference estimates with the estimates of the Logit model. This confirms that the selection of the treatment regions was not correlated to changes in the composition of the insured population over time. The standard errors in the Logit model are much smaller than in the difference-in-difference model. The effect of intensified screening on sickness absenteeism reports is significant and the $p$-value for significance of the effect on DI applications is 0.07 .

Recall from Section 4 that we can distinguish two effects from more intensive screening. It increases reintegration efforts, which in turn might increase re-employment probabilities of sick workers. And self-screening may prevent employers and workers to start the DI-application process. We argued that the effect of intensified screening on DI applications is a measure for the direct effect from increased reintegration effort, while the effect on 13 weeks sickness absenteeism reports is a measure for self-screening of potential DI benefit applicants. The empirical results show that the more intensive screening reduces both the incidence of 13 weeks sickness absenteeism reports and the number of DI benefit applications, which implies that both the direct effect and self-screening are important. To provide some more information on the relative importance of each of these effects, we provide in Table 7 the predicted number of sickness absenteeism reports and DI applications in 2003. Furthermore, Table 7 includes what the number of 13 weeks sickness absenteeism reports and DI applications would have been if the intensive screening would have been implemented nationwide or nowhere in the Netherlands. From the table we can see that nationwide implementation of intensified screening would reduce the number of sickness absenteeism reports by $5.2 \%$ and the number of DI applications by $4.8 \%$. This implies that self-screening is as important as the direct effect of increased reintegration activities, which suggests that moral hazard plays an important role in DI application behavior. Furthermore, the long-run effect of the intensified screening on DI applications will be larger than the effect estimated here. The long-run effect of the intensified screening on DI applications is the cumulative of the effect of self-screening and the direct effect due to increased reintegration activities.

\subsection{Effects on sanctions}

In the new regime the NSII was given the possibility to sanction the employer or employee. Since these sanctions did not exist prior to 2003, we cannot control for region specific unobserved 
effects. This reduces the reliability of the estimated effects of intensified screening on sanctions. The data on sanctions are also less informative than data on other outcome variables, we only observe the total number of sanctions applied in each region. So we cannot connect these sanctions to specific DI applications. Therefore, we should interpret the empirical results with care and we should not draw too strong conclusions about how more intensive screening influences the sanction rate. Furthermore, it should be noted that in 2003 almost all sanctions were imposed on the employer.

Table 8 provides the results from an OLS regression on the sanction rate in each region. We control for regional differences by including lagged (2002) 13 weeks sickness absenteeism reports, lagged DI benefit applications and lagged UI inflow rates. The estimation results show that the sanction rate is slightly lower in the treatment regions but this is very insignificant. However, sanction rates are higher in regions with a high DI application rate and low UI inflow rate. A propensity weighting estimator shows the same result. Using the estimator presented in Hirano, Imbens and Ridder (2003) we find an effect of more intensive screening on the sanction rate of -0.0298 with a standard error of $0.4864 .^{7}$ Of course, we should be careful in interpreting these effects, but these results suggest that in the treatment regions those who applied increased their reintegration efforts in response to stricter screening.

\subsection{Spillovers to $U I$}

The results show that self-screening by potential DI applicants is important. Potential DI applicants who choose not to start the process towards a DI application might use other channels to quit working. Autor and Duggan (2003) show for the US that there are substantial spillovers between DI and UI programs. If this is relevant here, we could expect more intensive screening to have a positive impact on the UI inflow. Table 9 presents Logit estimates for the effect of intensified screening on the UI inflow. We do not find a significant effect of the intensified screening on UI inflow and hence conclude that this policy does not cause substantial spillover effects between the inflow into DI and UI. More formally, we can use our estimates to construct the elasticity between DI applications and the UI inflow:

$$
\varepsilon=\frac{\partial Q_{U I}}{\partial Q_{D I}} \frac{Q_{D I}}{Q_{U I}}
$$

$Q_{U I}$ and $Q_{D I}$ are the number of individuals entering UI and DI respectively. Since we do not have a consistent estimate of the direct effect of $Q_{D I}$ and $Q_{U I}$ we can rewrite (3) as:

\footnotetext{
7 When applying this method the propensity score was specified as a Logit model and included the same
} regressors as the OLS regression of Table 8. 
$\varepsilon=\frac{\partial Q_{U I}}{\partial Q_{D I}} \frac{Q_{D I}}{Q_{U I}}=\frac{\partial Q_{U I} / \partial T}{\partial Q_{D I} / \partial T} \frac{Q_{D I}}{Q_{U I}}=\frac{\partial P_{U I} / \partial T}{\partial P_{D I} / \partial T} \frac{P_{D I}}{P_{U I}}$

$P_{U I}$ and $P_{D I}$ are the inflow probabilities into UI and DI, respectively and estimates of the treatment effect $(T)$ on inflow probabilities, $\partial P_{k} / \partial T, k=U I, D I$, can be obtained from Tables 6 and 9. Using these we get an estimated elasticity of 0.13 . The standard error of this elasticity (computed by the delta method) equals 0.21 . We conclude once more that we cannot reject that there are no spillovers between DI and UI. This seems to contradict the finding of Autor and Duggan (2003). However, it should be noted that they estimate an overall elasticity between UI and DI, while we estimate this elasticity at the margin of the more intensive screening.

Not all workers who are eligible for DI benefits are also eligible for UI benefits. In particular, eligibility for UI requires that the worker has some recent work history. This is not required for DI. The work requirement may be relevant for young workers who have little prior experience and this may downward bias the average effect of the intensified screening. We therefore also estimated a Logit model for inflow into UI, where we allowed the effect of the more intensive screening to vary with age and gender. These results are reported in Table 10. For none of the age-gender groups we find spillover effects into UI. ${ }^{8}$

\subsection{Sensitivity analyses}

Table 6 showed that sickness risks and DI application probabilities vary with individual characteristics. Indeed, the incentives that individual workers face differ. As discussed in Subsection 2.1 both the entitlement period of initial DI benefits and the level of the follow-up benefits increase with the age of entering DI. So the incentive to apply for a DI varies with age and therefore also the effect of intensified screening may vary with age of the applicant.

Therefore, we estimate a Logit model that allows for age and gender specific effects of intensified screening. The marginal effects reported in Table 11 show that the intensified screening reduced 13 weeks sickness absenteeism reports for almost all age groups and there does not seem to be any clear effect between the magnitude of the effect and the worker's age. Except for the oldest age group the effect of the stricter screening on 13 weeks sickness absenteeism reports is slightly higher for women, but there are no clear age specific effects. As regards DI applications the more intensive screening only affects women and the effect increases with the woman's age. A possible reason for this finding is that married females are often secondary income earners in the family and that non-market alternatives of time use (e.g. child care) are more relevant for this group. In our data we do not observe the marital status, nor do we have information on the presence of children. We therefore could not explore this issue any further.

Table 1 showed that case workers in the experiment region Apeldoorn chose to use more

8 Alternatively, we could examine inflow into means-tested welfare to check for spillover effects. However, welfare is organized at the level of municipalities and our administrative records from the NSII are therefore not informative on inflow into welfare. 
face-to-face contacts with workers to intensify the screening. In Hengelo the case workers chose another strategy, they visited employers more regularly. If indeed the employer is the most relevant decision making agent in this DI application process, one might expect the strategy in Hengelo to be more effective. To investigate this issue we have estimated a Logit model that allows for different effects for Apeldoorn and Hengelo. These effects are reported in Table 12. For 13-week sickness absence we found strong and significant effects for Hengelo, but not for Apeldoorn. The effect is equivalent to a reduction of about 10\% in 13-weeks sickness absenteeism rates in Hengelo. The effects on DI applications do not differ between both regions and are in size similar to the results in Table 6. From this we can conclude that the employer is indeed the most relevant decision maker and that self-screening of potential DI applicants is triggered through the employer.

\subsection{Cost-benefit analysis}

We can use our estimation results to perform a cost-benefit analysis of intensified screening. For this we use the results of Table 7 and compare a situation where the more intensive screening is applied nationwide to a situation where only the standard screening procedure is applied. The results in Table 7 apply to the year 2003. We argued earlier that the number of DI applications in 2003 was only affected by direct effects of work resumption during sickness absenteeism and not yet by self-screening of potential DI applicants. Therefore, it is likely that in the long-run equilibrium the costs will be lower and the benefits higher. Without intensive screening each case worker handles on average 110 applications for DI benefits per year. For all 34,196 applications about 311 case workers are needed. Intensified screening requires an additional time investment of the case worker of $9.4 \%$ of the total time spend on each DI application. Since also fewer applications per year should be handled only 13 additional case workers are required, which cost approximately 1.32 million euros per year.

More intensive screening induces a reduction of 1,633 DI applications per year. Recall that an application is made after 39 weeks of sickness absenteeism, while DI benefits entitlement only starts after 52 weeks of sickness absenteeism. Only $47 \%$ of the applications lead to an actual enrolment into the DI program. The average DI benefit is 11,745 euro per year; the average benefits duration is 12.9 years. ${ }^{9}$ If we use a discount rate of $5 \%$ per year, the expected present value of future DI benefits payments is slightly less than 85,000 euros. Hence, the total amount of averted DI benefits payments of stricter screening are around 64.8 million euros.

This cost-benefit analysis assumes that the composition of the inflow into DI remains unchanged after the intensified screening has been nationwide introduced. In particular, annual exit probabilities remain unchanged and the average benefits level does not change. Of course, it can be argued that more intensive screening and the subsequent work resumption by sick workers will shift the population flowing into DI towards individuals who have worse labor market

9 The gross annual exit probabilities from disability insurance are in the first year 0.16 , in the second year 0.17 , in the third year 0.10 , in the fourth year 0.07 and around 0.06 afterwards. 
prospects and thus on average longer DI spells. This reduces the expected benefits of intensive screening. On the other hand, the cost-benefit analysis does not take into account that intensive screening also significantly reduces the 13 weeks sickness absenteeism report rate, which reduces administrative costs. The main conclusion of these rough calculations is that the costs of implementing the procedure of intensified screening are only a small fraction of the benefits.

\section{Conclusions}

In the Netherlands, if a worker becomes sick, there is a one year waiting period of sickness absenteeism before the worker can enroll into DI. Applications for DI benefits should be made during the $39^{\text {th }}$ week of sickness absence. These applications are only considered admissible if they are accompanied by a reintegration report, containing a detailed description of the reintegration activities of the employer and worker during the period of sickness absenteeism. If the report is delayed, incomplete, or proves that the reintegration efforts were insufficient the claim is not processed and the case worker of the NSII may start a sanction procedure.

In the paper we consider a policy of more intensive screening of the reintegration reports by the case workers of the National Social Insurance Institute (NSII). With no or little screening, worker and employer can decide to devote none or only a minimal effort in trying to get the worker back to work. Intensive screening forces employers and workers to devote more effort in getting the sick worker back to work. This increased reintegration effort can have a direct effect on work resumption during sickness absence. Furthermore, more intensive screening reduces the attractiveness of the DI program to potential applicants (and to employers), which can trigger a mechanism of self-selection by potential applicants (Parsons, 1991).

To investigate the consequences of intensified screening we have setup an experiment. We instructed case workers at two local DI offices to implement a more intensive screening regime of the reintegration activity reports than in the rest of the Netherlands. This provides truly exogenous variation in the screening intensity, which distinguishes this paper from previous contributions to this literature.

We use data from the administrative records of NSII and find that intensified screening leads to a decrease in both 13 weeks sickness absence reports and DI applications. We argue that the decline in 13 weeks sickness absence reflects self-screening by potential DI applicants and the reduction in DI applications measures work resumption during sickness absenteeism. The empirical results show that the intensified screening causes both self-selection and work resumption during sickness absenteeism. The long-run effect on DI applications is the cumulative of the effect of self-screening and of the direct effect due to work resumption. A crude costbenefit analysis shows that the costs of the intensive screening are only a small fraction of the benefits. Even though self-screening is substantial we do not find negative spillovers of the intensified screening to the inflow into UI. Furthermore, sensitivity analyses show that screening is more effective when applied to the employer than to the worker. 


\section{References}

Autor, D.H. and M.G. Duggan (2003), "The rise in the disability rolls and the decline in unemployment", Quarterly Journal of Economics 118, 157-205.

Bound, J. and R.V. Burkhauser (1999), "Economic analysis of transfer programs targeted on people with disabilities", in O.C. Ashenfelter and D. Card (eds.), Handbook of Labor Economics, Volume 3C, Amsterdam-New York: North-Holland.

Gruber, J. (2000), "Disability Insurance Benefits and Labor Supply”, Journal of Political Economy 108, 1162-1183.

Halpern, J. and J.A. Hausman (1986), "Choice under uncertainty: a model of applications for the social security disability insurance program”, Journal of Public Economics 31, 131-161.

Hirano, K., G.W. Imbens and G. Ridder (2003), "Efficient estimation of average treatment effects using the estimated propensity score", Econometrica 71, 1161-1189.

Johansson, P. and M. Palme (1996), "Do economic incentives affect work absence? Empirical evidence using Swedish micro data”, Journal of Public Economics 59, 195-218.

Johansson, P. and M. Palme (2002), “Assessing the effect of a public policy on worker absenteeism", Journal of Human Resources 37, 381-409.

OECD (2003), Transforming Disability into Ability: policies to promote work and income security for disabled people.

OECD (2004), Economic Survey of the Netherlands.

Parsons, D.O. (1991), "Self-screening in targeted public transfer programs", Journal of Political Economy 99, 859-876. 
Figure 1: DI benefit recipients: stock and inflow 1970-2003.

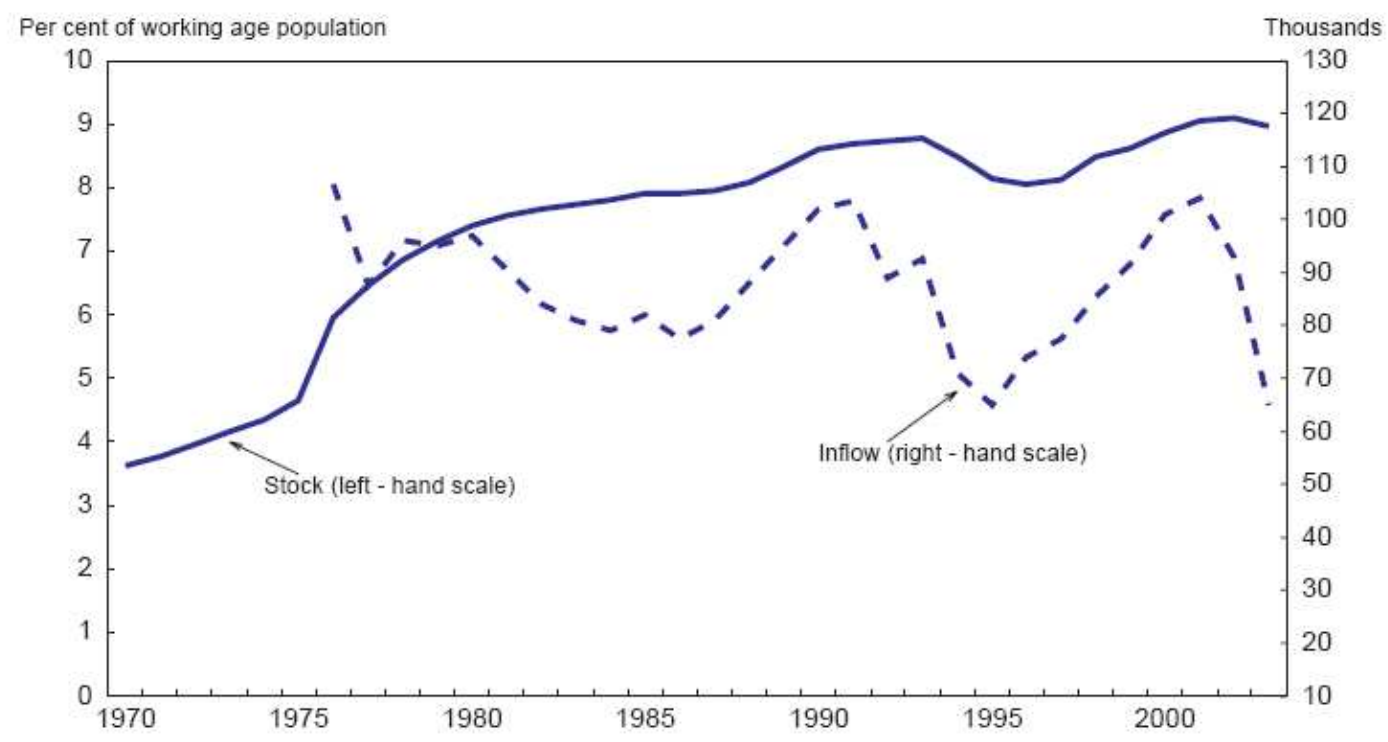

Source: OECD (2004). 
Table 1: Difference in screening intensity between treatment and control regions.

\begin{tabular}{lccc}
\hline \hline & \multicolumn{2}{c}{ Treatment regions } & \multirow{2}{*}{ Control } \\
& Apeldoorn & Hengelo & regions \\
\hline Only on paper & $4 \%$ & $14 \%$ & $25 \%$ \\
Telephonic contact with employer & $33 \%$ & $34 \%$ & $52 \%$ \\
Telephonic contact with worker & $14 \%$ & $14 \%$ & $23 \%$ \\
Telephonic contact occupational health agency & $3 \%$ & $12 \%$ & $32 \%$ \\
Visit to employer & $9 \%$ & $41 \%$ & $7 \%$ \\
Face to face contact with worker & $77 \%$ & $41 \%$ & $18 \%$ \\
Unknown & $4 \%$ & $2 \%$ & \\
\hline \hline
\end{tabular}

Table 2: Some descriptives of the data.

\begin{tabular}{lccc}
\hline \hline & 2001 & 2002 & 2003 \\
\hline Number of insured individuals & $3,352,516$ & $3,346,515$ & $3,277,887$ \\
Sickness absenteeism (13 weeks) & 0.0473 & 0.0446 & 0.0399 \\
DI applications & 0.0150 & 0.0137 & 0.0104 \\
UI inflow & 0.0304 & 0.0433 & 0.0587 \\
Sanction rate & - & - & 0.0524 \\
Fraction female & 0.317 & 0.320 & 0.320 \\
Age -34 years & 0.470 & 0.457 & 0.441 \\
Age 35-44 years & 0.266 & 0.271 & 0.276 \\
Age 45-54 years & 0.192 & 0.192 & 0.195 \\
Age 55- years & 0.072 & 0.080 & 0.089 \\
\hline \hline
\end{tabular}

Table 3: Pre-experiment outcomes in treatment and control regions (year 2002).

\begin{tabular}{lcc}
\hline \hline & Treatment Regions & Control Regions \\
\hline Sickness absenteeism & $0.04823(0.00079)$ & $0.04483(0.00433)$ \\
DI applications & $0.01376(0.0001)$ & $0.01392(0.00300)$ \\
UI inflow & $0.04228(0.00542)$ & $0.04436(0.09167)$ \\
\hline \hline
\end{tabular}

Standard errors in parentheses.

Table 4: Test for (conditional) random selection of treatment regions: difference-in-difference estimates (2002 compared to 2001).

\begin{tabular}{lccc}
\hline \hline & Sickness absenteeism & DI applications & UI inflow \\
\hline Trend & $-0.00291(0.00018)$ & $-0.00142(0.00023)$ & $0.01257(0.00106)$ \\
Treatment region & $0.00072(0.00063)$ & $0.00113(0.00082)$ & $0.00041(0.00380)$ \\
\hline \hline
\end{tabular}

Standard errors in parentheses. 
Table 5: The effect of intensified screening: regional difference-in-difference estimates (2003 compared to 2002).

\begin{tabular}{lcc}
\hline \hline & Sickness absenteeism & DI applications \\
\hline Trend & $-0.00455(0.00028)$ & $-0.00320(0.00021)$ \\
Treatment (intensified screening) & $-0.00213(0.00103)$ & $-0.00048(0.00076)$ \\
\hline \hline
\end{tabular}

Standard errors in parentheses.

Table 6: The effect of intensified screening: marginal effects from individual Logit estimates.

\begin{tabular}{lcc}
\hline \hline & Sickness absenteeism & DI applications \\
\hline Trend & $-0.00397(0.00153)$ & $-0.00091(0.00084)$ \\
Treatment (intensified screening) & $-0.00223(0.00057)$ & $-0.00059(0.00032)$ \\
Male -34 years & - & - \\
Female -34 years & $0.02286(0.00030)$ & $0.01028(0.00017)$ \\
Male 35-44 years & $0.02383(0.00027)$ & $0.00791(0.00017)$ \\
Female 35-44 years & $0.04072(0.00032)$ & $0.01593(0.00018)$ \\
Male 45-54 years & $0.03467(0.00028)$ & $0.01286(0.00016)$ \\
Female 45-54 years & $0.04680(0.00035)$ & $0.01926(0.00019)$ \\
Male 55- years & $0.04403(0.00032)$ & $0.01436(0.00019)$ \\
Female 55- years & $0.04835(0.00051)$ & $0.01861(0.00027)$ \\
\hline \hline
\end{tabular}

In this regression is also controlled for region, sector and interactions between the sector and the time trend (in total 114 additional parameters). Standard errors in parentheses.

Table 7: Simulations for sickness absence and DI applications under different screening scenarios applying to 2003 using the estimates from the Logit model.

\begin{tabular}{lcc}
\hline \hline & Sickness absenteeism & DI applications \\
\hline Predicted in current situation & 130,423 & 34,066 \\
Without nationwide intensive screening & 130,997 & 34,196 \\
With nationwide intensive screening & 124,236 & 32,563 \\
\hline \hline
\end{tabular}

Table 8: The effect of intensified screening on sanctions: results from an OLS regression on the sanction probability in 2003.

\begin{tabular}{lr}
\hline \hline & Sanctions \\
\hline Intercept & $0.0648(0.0483)$ \\
Treatment (intensified screening) & $-0.0064(0.0175)$ \\
Sickness absenteeism reports in 2002 & $-0.7398(1.4198)$ \\
DI applications in 2002 & $-4.1712(1.8475)$ \\
UI inflow in 2002 & $1.7875(0.6013)$ \\
\hline $\mathrm{R}^{2}$ & 0.878 \\
\hline \hline
\end{tabular}

Standard errors in parentheses. 
Table 9: The effect of intensified screening: marginal effects from individual Logit estimates.

\begin{tabular}{lc}
\hline \hline & UI inflow \\
\hline Stricter screening & $-0.00043(0.00065)$ \\
Trend & $0.02217(0.00122)$ \\
Male -34 years & - \\
Female -34 years & $0.01547(0.00027)$ \\
Male 35-44 years & $0.00365(0.00027)$ \\
Female 35-44 years & $0.02418(0.00032)$ \\
Male 45-54 years & $0.00470(0.00030)$ \\
Female 45-54 years & $0.02240(0.00038)$ \\
Male 55- years & $0.01614(0.00036)$ \\
Female 55- years & $0.02802(0.00059)$ \\
\hline \hline
\end{tabular}

In this regression is also controlled for region, sector and interactions between the sector and the time trend (in total 114 additional parameters). Standard errors in parentheses.

Table 10: The effects of intensified screening by age and gender on UI inflow: marginal effects from Logit estimates.

\begin{tabular}{lcc}
\hline \hline & \multicolumn{2}{c}{ UI inflow } \\
\hline Intensified screening interacted with: & \\
Male -24 years & 0.00001 & $(0.00095)$ \\
Female -24 years & -0.00015 & $(0.00115)$ \\
Male 35-44 years & -0.00063 & $(0.00111)$ \\
Female 35-44 years & -0.00065 & $(0.00151)$ \\
Male 45-54 years & -0.00053 & $(0.00126)$ \\
Female 45-54 years & -0.00044 & $(0.00184)$ \\
Male 55- years & -0.00141 & $(0.00166)$ \\
Female 55- years & -0.00116 & $(0.00305)$ \\
\hline \hline
\end{tabular}

In this regression is also controlled for a time trend, gender interacted with age, region, sector and interactions between the sector and the time trend (in total 122 additional parameters). Standard errors in parentheses. 
Table 11: Effects of intensified screening by age and gender: marginal effects from individual Logit estimates.

\begin{tabular}{llrll}
\hline \hline & \multicolumn{2}{c}{ Sickness absenteeism } & \multicolumn{2}{c}{ DI applications } \\
\hline Intensified screening interacted with: & & & & \\
Male -34 years & $-0.00075(0.00110)$ & 0.00105 & $(0.00066)$ \\
Female -34 years & $-0.00253(0.00123)$ & -0.00124 & $(0.00070)$ \\
Male 35-44 years & $-0.00281(0.00099)$ & -0.00008 & $(0.00059)$ \\
Female 35-44 years & $-0.00301(0.00137)$ & -0.00143 & $(0.00077)$ \\
Male 45-54 years & $-0.00184(0.00099)$ & -0.00019 & $(0.00057)$ \\
Female 45-54 years & $-0.00381(0.00156)$ & -0.00171 & $(0.00083)$ \\
Male 55- years & $-0.00239(0.00120)$ & -0.00060 & $(0.00073)$ \\
Female 55- years & $-0.00022(0.00245)$ & -0.00459 & $(0.00154)$ \\
\hline \hline
\end{tabular}

In this regression is also controlled for a time trend, gender interacted with age, region, sector and interactions between the sector and the time trend (in total 122 additional parameters). Standard errors in parentheses.

Table 12: The effect of intensified screening for both treatment regions: marginal effects from individual Logit estimates.

\begin{tabular}{lcc}
\hline \hline & Sickness absenteeism & \multicolumn{2}{c}{ DI applications } \\
\hline Apeldoorn & $0.00005(0.00081)$ & $-0.00057(0.00047)$ \\
Hengelo & $-0.00413(0.00076)$ & $-0.00058(0.00042)$ \\
\hline \hline
\end{tabular}

In this regression is also controlled for a time trend, gender interacted with age, region, sector and interactions between the sector and the time trend (in total 122 additional parameters). Standard errors in parentheses. 